\title{
DESCRIÇÃO DO CICLO DE VIDA DE Methona themisto (LEPIDOPTERA: NYMPHALIDAE) E VIABILIDADE DE CRIAÇÃO EM BORBOLETÁRIO
}

\author{
Gabriela Barone Volce da Silva1, Andressa Santoro², Satiko Nanya ${ }^{3}$ \\ ${ }^{1}$ Acadêmico do curso de Ciências Biológicas, Universidade Estadual de Maringá - UEM. PIC-UEM gabrielabaronevolce@hotmail.com \\ ${ }^{2}$ Acadêmico do curso de Ciências Biológicas, Universidade Estadual de Maringá - UEM. PIC-UEM andressasantoro12@hotmail.com \\ ${ }^{3}$ Orientadora, Doutora, Departamento de Biotecnologia, Genética e Biologia Celular, UEM. Laboratório de Controle Biológico, \\ Morfologia e Citogenética de Insetos. snanya@uem.br
}

\section{RESUMO}

Methona themisto são insetos da ordem Lepidoptera, família Nymphalidae. Essa espécie utiliza como planta hospedeira a Brunfelsia uniflora conhecida popularmente como manacá-de-cheiro, onde ocorre a postura de ovos e serve de alimento para as lagartas. O objetivo desta pesquisa foi realizar a criação de $M$. themisto e caracterizar a morfologia de cada fase do ciclo de vida, bem como avaliar a viabilidade para criação em borboletário. Ovos e lagartas foram coletados no Campus sede da Universidade Estadual de Maringá, em Março de 2018. A criação e manutenção foi realizado no Laboratório de Controle Biológico, Morfologia e Citogenética de Insetos em potes de polipropileno de 2 litros e ramos de Brunfelsia sp., colocados em frascos de vidro contendo água. Esse estudo permitiu determinar o ciclo de vida da postura dos ovos até a emergência do adulto, sendo 6 dias a fase de ovo, 27 dias a fase larval, 9 dias a fase de pupa, totalizando 42 dias. A fase larval apresenta 5 instares caracterizadas por meio do tamanho das cápsulas cefálicas sendo no $1^{\circ}$ instar de $0,8 \mathrm{~mm}, 2^{\circ}$ instar $1 \mathrm{~mm}$, $3^{\circ}$ instar $1,5 \mathrm{~mm}$, $4^{\circ}$ instar $2 \mathrm{~mm}$ e $5^{\circ}$ instar $3 \mathrm{~mm}$. O tamanho da lagarta variou de $4 \mathrm{~mm}$ após a eclosão do ovo a $60 \mathrm{~mm}$ no final da fase larval. A taxa de mortalidade foi baixa durante o manejo o que nos permitiu concluir que a espécie Methona themisto apresenta um desenvolvimento favorável às condições laboratoriais, permitindo assim viabilidade para manutenção em borboletário.

PALAVRAS-CHAVES: Fase do desenvolvimento; Lagarta; Morfologia larval; Viabilidade.

\section{INTRODUÇÃO}

No reino Animalia o grupo mais abundante e rico em diversidade é formado pelos insetos. Alguns autores utilizam os termos hexápodes e insetos como sinônimos. No entanto, o termo Hexapoda abrange artrópodes que possuem três pares de pernas, enquanto o termo Insecta inclui, além disso, aqueles com peças bucais externas (RAFAEL et al., 2012).

Os insetos e o homem têm uma estreita relação, que vem desde os primórdios da existência dos seres humanos. Os insetos fornecem produtos como seda, cera e mel, citando apenas alguns exemplos, podem ter importância médica e farmacêutica, há medicamento extraídos deles, um inseto pode controlar a população de outro, ou seja, fazer o controle biológico e eles também têm importância imprescindível na polinização, que é a relação de mutualismo entre insetos e plantas mais conhecidas. As principais ordens que realizam esse processo são Coleoptera, Hymenoptera, Diptera e Lepidoptera (BUZZI, 2002; TRIPLEHORN; JONNSON, 2011).

A ordem Lepidoptera foi proposta por Linnaeus em 1758 e inclui borboletas e mariposas. Seu nome origina-se do grego e refere-se a presença de escamas (lepis) cobrindo as asas (pteron) dos insetos que pertencem a este Ordem, embora se saiba que as escamas também cobrem seus corpos e demais apêndices. $O$ aparelho bucal desses insetos é do tipo sugador com uma espirotromba delgada, longa e espiralada (RAFAEL et al, 2012).

As borboletas e mariposas são holometábolas, têm metamorfose completa em seu 
ciclo de vida, com número variado de mudas. As larvas de lepidóptera podem ser predadas por pássaros, aranhas e ácaros, podendo ocorrer até mesmo o parasitismo nos ovos e a predação das lagartas por outros animais, a maioria sendo insetos. A maior parte das lagartas se alimenta de folhas de plantas, enquanto os adultos se alimentam de pólen e néctar das flores, em sua maioria. Não é incomum que a voracidade das lagartas causem prejuízos as plantações (RAFAEL et al, 2012; BUZZI, 2002).

A família Nymphalidae possui como uma das sinapomorfias a "presença de três carenas longitudinais na superfície ventral das antenas” (RAFAEL et al., 2012, p. 672). Ademais suas pernas anteriores são muito reduzidas e não são utilizadas para locomoção. Esse grupo inclui as borboletas coloridas mais admiradas e conhecidas pelas pessoas, com diversos padrões de coloração nas asas. Os adultos possuem hábito diurno e tamanho médio a grande. Suas larvas também possuem coloração variada, bem como a forma. As borboletas pertencentes a essa família tem ampla distribuição, vivem em ambientes muito variados, sendo ausentes somente nos pólos. As relações que elas mantêm com suas plantas hospedeiras são de grande complexidade e número (RAFAEL et al., 2012; WATSON; DALLWITZ, 2003; TRIPLEHORN; JONNSON, 2011).

A subfamília Ithomiinae inclui exclusivamente borboletas Nymphalidae da região neotropical, ou seja, da região que compreende a América do Sul e a América Central. No século XIX, devida as suas semelhanças, as borboletas dessa subfamília foram utilizadas para exemplificar teorias de mimetismo de Bater e Muller. Elas são boas indicadoras de qualidade ambiental (BROWN et al, 1994, apud BECCALONI 1997). Pertence a esta subfamília a espécie Methona themisto (Hubner, 1818), comumente encontrada em locais urbanos nas regiões sul e sudeste do Brasil, embora ocorra desde o Pará até o Rio Grande do Sul (SILVA et al, 1968, apud NARDI et al, 2006). A alimentação de suas lagartas consiste exclusivamente em folhas de plantas do gênero Brunfelsia (Linnaeus, 1822), especialmente da espécie Brunfelsia uniflora, cujo nome popular é manacá-de-cheiro (NARDI et al., 2006).

Suas lagartas apresentam listras brilhantes com coloração amarela e preta, intercaladas. Morfologicamente, os adultos apresentam asas com coloração alaranjada, preta e branca, e corpo preto com ponto branco e amarelo. São borboletas urbanas de fácil visualização, com voo lento e grande tolerância a presença humana (RUSZCZYK; NASCIMENTO, 1999).

O ciclo de vida das espécies de Methona foi descrito em alguns trabalhos, no entanto, seus estágios imaturos e desenvolvimento larval ainda são pouco documentados. Barbosa e Costa (2013) descrevem alguns aspectos da duração e morfologia do ovo, larva e pupa.Methona themisto quando capturados, os adultos ficam imóveis por alguns segundos, ilustrando o curioso fenômeno da tanatose. Suas larvas são vistosas por apresentarem coloração conspícua alimentando-se das folhas de Brunfelsia sp., (Solanaceae), planta ornamental conhecida no Brasil como "manacá de cheiro" ou "jasmim manacá", presente em praças e jardins. Os imaturos e adultos de $M$. themisto tem um grande valor estético e educativo para os cidadãos. Apesar de ser um inseto popular, há poucas informações publicadas sobre a biologia, ecologia e morfologia de M.themisto em áreas urbanas, sendo consideradas pragas do manacá-de-cheiro. Assim, o objetivo desta pesquisa será realizar a criação e manutenção de Methona themisto em laboratório para avaliar a viabilidade para criação em borboletário e descrever a morfologia das diferentes fases, caracterizando o período de desenvolvimento de cada uma das fases. 
Ovos e lagartas de Methona themisto foram coletados em março de 2018 no campus da Universidade Estadual de Maringá, munícipio de Maringá (PR), localizada a 551 metros de altitude, Latitude: $23^{\circ} 25^{\prime} 38^{\prime \prime}$ Sul Longitude: $51^{\circ} 56^{\prime} 15^{\prime \prime}$ Oeste, com média pluviométrica anual de 1.500 mililitros e média anual de temperatura $21,95^{\circ} \mathrm{C}$ e criados no Laboratório de Controle Biológico, Morfologia e Citogenética de Insetos no Bloco H-67, sala 7A, DBC/UEM, a temperatura ambiente. Os ovos e larvas juntamente com os ramos da planta hospedeira foram armazenados em potes de polipropileno para manutenção da criação. As pupas foram mantidas também em potes com algodão úmido para manter a umidade necessária ao seu desenvolvimento. A manutenção dos potes foi feita diariamente, observando-se as alterações ocorridas durante o desenvolvimento e fazendo anotações para caracterizar o período de cada uma das fases. Ao atingirem a fase adulta foi feito a sexagem e os casais de borboletas foram transferidos para cestos telados, contendo 2 dietas, um deles constituído de mel, levedura e água e o outro algodão com açúcar embebido em água, e um ramo de manacá para postura de ovos, os quais foram trocados a cada dois dias, com observação diária para verificar a presença de ovos nas folhas do ramo e anotar a mortalidade. Os demais espécimes foram liberados no interior do borboletário e o monitoramento foi realizado para verificar a viabilidade de $M$. themisto em cativeiro. As análises da morfologia foram feitas com auxílio do estereomicroscópio e para documentação fotográfica utilizou-se câmera fotográfica digital, procedendo a descrição e discussão dos resultados obtidos.

\section{RESULTADOS E DISCUSSÃO}

Methona themisto são insetos que apresentam desenvolvimento holometábolo, ou seja, metamorfose completa. A primeira etapa do ciclo de vida é o desenvolvimento embrionário. Os ovos dessa espécie apresentam coloração branca leitosa de formato ovalado, quando o ovo é fértil (Fig. 1A). Os ovos fertilizados após cerca de 5 dias começam a escurecer em decorrência ao desenvolvimento da larva e a formação da cápsula cefálica, a eclosão acontece entre o $6^{0}$ e $7^{0}$ dia (Fig.1B). Os ovos não fertilizados apresentam aspecto transparente e o cório poroso (Fig. 1C). Com a eclosão do ovo se dá a fase seguinte, de larva ou lagarta. A lagarta apresenta doze listras pretas e amarelas intercaladas ao longo do corpo vermiforme que é recoberto por cerdas não urticantes, possuem falsas pernas com ganchos em sua base, os quais servem para segurar 0 alimento. Outra característica do período larval é o aparelho bucal mastigador. Durante o desenvolvimento da lagarta ocorrem cinco fases conhecidas como instares necessárias para o crescimento. A cada mudança de instar a lagarta elimina a cápsula cefálica dando lugar a uma nova e também ocorre a eliminação concomitante da epiderme. O tamanho da cápsula cefálica é importante para definir cada instar larval onde no $1^{\circ}$ instar o tamanho é de 0,8 milímetros $(\mathrm{mm})$, no $2^{\circ}$ instar $1 \mathrm{~mm}$, no $3^{\circ}$ instar $1,5 \mathrm{~mm}$, no $4^{\circ}$ instar $2 \mathrm{~mm}$ e no $5^{\circ}$ instar 3mm, como pode se observar na Figura 2. $01^{\circ}$ instar (Fig. 3A) larval tem duração média de 4 dias e a larva cresce aproximadamente $2 \mathrm{~mm}$ a $3 \mathrm{~mm}$ alcançando entre $6 \mathrm{~mm}$ e $7 \mathrm{~mm}$, ao fim da ecdise e a troca da cápsula cefálica. $\mathrm{O} 2^{\circ}$ instar larval (Fig.3B) tem o mesmo tempo de duração, 4 dias, e o crescimento da larva é de aproximadamente $7 \mathrm{~mm}$ atingindo um tamanho de $14 \mathrm{~mm}$ no final da muda. $\mathrm{O} 3^{\circ}$ instar larval (Fig. $3 \mathrm{C}$ ) tem duração também de 4 dias e o crescimento é de aproximadamente $11 \mathrm{~mm}$ cuja larva ou lagarta chega a 
aproximadamente $25 \mathrm{~mm}$. $\mathrm{O} 4^{\circ}$ instar larval (Fig. 3D) tem duração em torno de 5 a 6 dias e o crescimento é em torno de $15 \mathrm{~mm}$ e a lagarta chega a $40 \mathrm{~mm}$. $\mathrm{O} 5^{\circ}$ instar larval (Fig. 3E) e último, demora cerca de 8 a 10 dias e a larva cresce aproximadamente $20 \mathrm{~mm}$, atingindo o tamanho final de $60 \mathrm{~mm}$. Assim, o período de lagarta leva de 25 a 28 dias, em média 27 dias e o tamanho varia de aproximadamente $4 \mathrm{~mm}$ no primeiro instar a $60 \mathrm{~mm}$ no final do quinto instar. Em seguida, a lagarta para de se alimentar, fica mais lenta e a coloração se torna opaca onde ocorre a liberação de seda para fixação desta e inicia-se a próxima fase de pupa ou crisálida ou casulo.
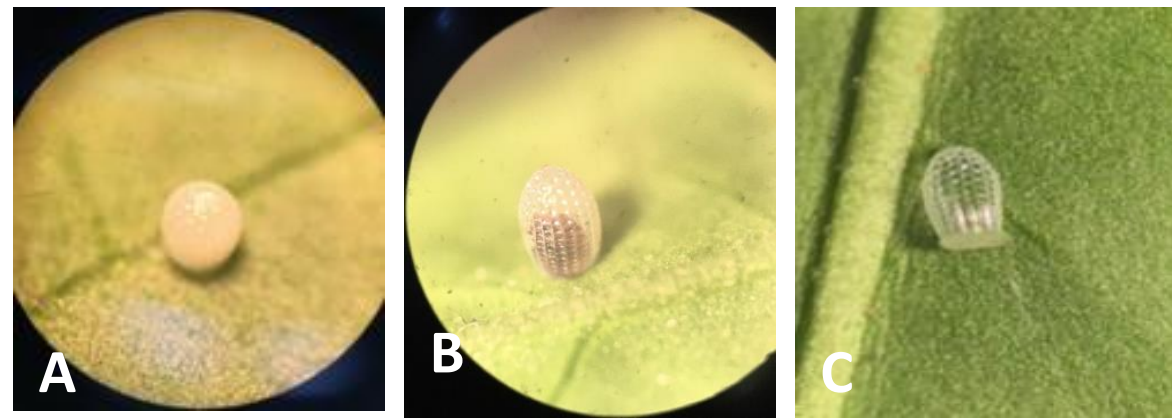

Figura 1- Ovos de Methona themisto. A. Ovo fértil; B, Ovo infértil; C. Ovo prestes a eclodir. Aumento 16X.

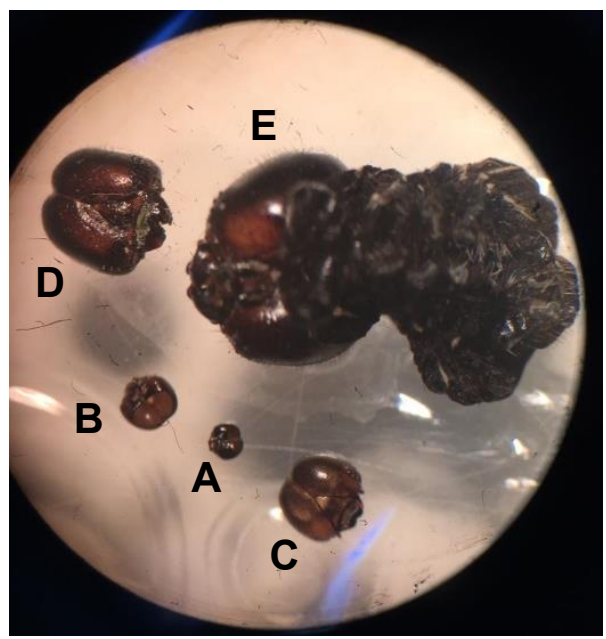

Figura 2- Cápsulas cefálicas de lagartas de Methona themisto. A. $1^{\circ}$ instar; B. $2^{\circ}$ instar; C. $3^{\circ}$ instar; D. $4^{\circ}$ instar; E. 5o instar. Aumento de $16 \mathrm{X}$.
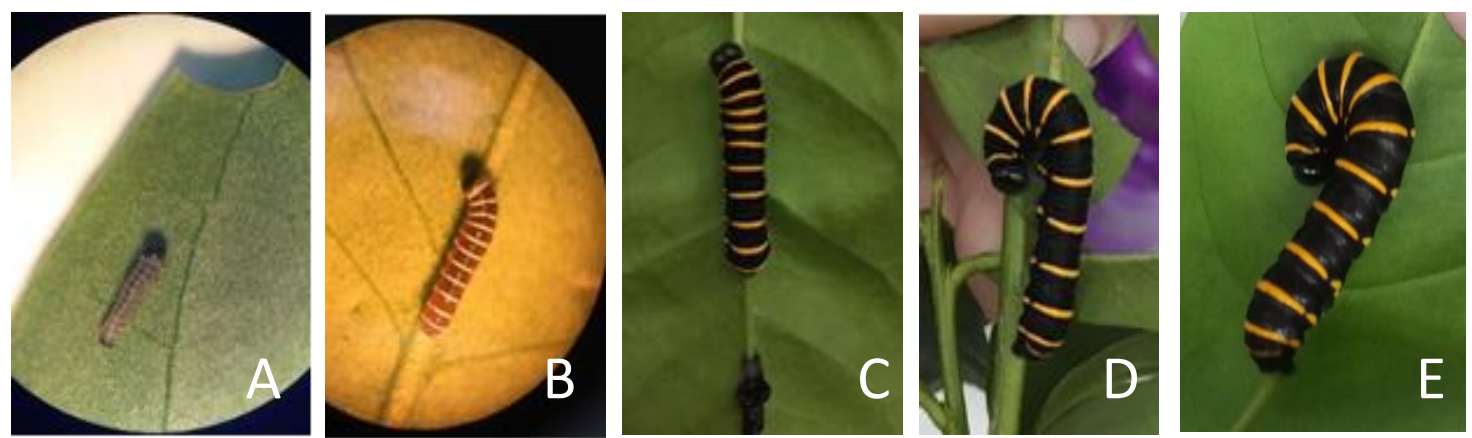

Figura 3- Lagartas de Methona themisto. A. $1^{\circ}$ instar; B. $2^{\circ}$ instar; C. $3^{\circ}$ instar; D. $4^{\circ}$ instar; E. $5^{\circ}$ instar. Aumento de 16X. 
A pupa é do tipo obtecta apresentando coloração amarelo vibrante e com algumas machas pretas ao seu redor que variam de forma, tamanho e quantidade (Fig. 4A). Ao decorrer do desenvolvimento da pupa, conforme a emergência do inseto vai se aproximando, a coloração se torna escura e as asas escuras da borboleta começam a transparecer em sua superfície (Fig. 4B). O adulto emerge após 8 a 10 dias de pupação, em média 9 dias. Algumas borboletas não conseguem emergir e acabam ficando presas na pupa (Fig. 4C). Após 39 a 45 dias, em média 42 dias, o adulto emerge do interior da pupa. Nos primeiros 50 minutos em contato com o meio exterior, a borboleta recém-emergida permanece em repouso sobre sua crisálida para secagem das asas, preparando-se para 0 voo (Fig. 4D).
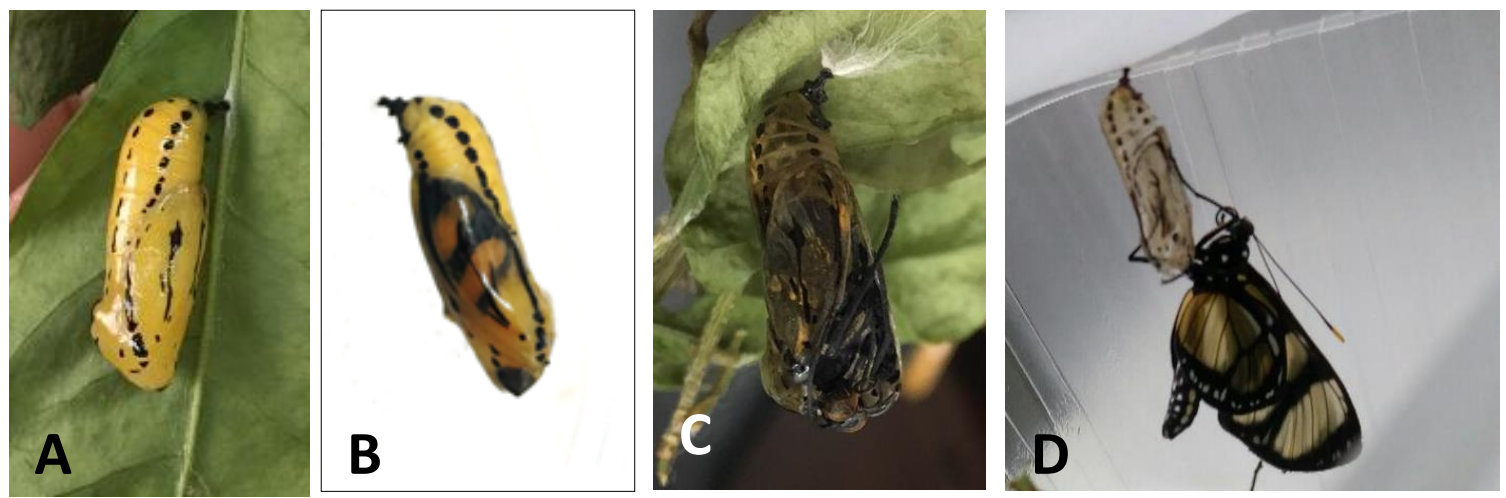

Figura 4- Methona themisto. A. Pupa jovem; B. Pupa tardia; C. Adulto preso na pupa; D. Adulto recémemergido secando as asas.

Como a maioria dos insetos adultos, os lepidópteros apresentam o corpo dividido em cabeça, tórax e abdômen. Na cabeça estão presentes os apêndices cefálicos e um par de olhos compostos e hemisféricos. Os apêndices cefálicos são representados por um par de antenas, labro, maxilas e lábio. As antenas são longas, clavadas e se encontram localizadas nas margens dorsolaterais do esclerito frontoclipeal. O labro, maxila e lábio constituem o aparelho bucal sugador maxilar exclusivo desses insetos. As maxilas dão origem a espirotromba, apêndice longo e espiralado que se alonga para retirar néctar ou outros fluidos açucarados do interior de plantas e se enrola quando em repouso. No tórax estão articulados os 3 pares de pernas ambulatórias que não apresentam nenhuma característica evolutiva, ou seja, esses apêndices são utilizados somente para equilíbrio, pois a locomoção principal é feita a partir do voo onde os 2 pares de asas membranosas providas de minúsculas escamas são utilizadas. Em suas bordas superiores, ou seja, na parte de cima da asa, região onde há mais escamas, o preto com manchas brancas é predominante (Fig. 5A), na parte inferior os pontilhados brancos se encontram ausentes (Fig. 5B). A parte mais interna, região onde as vênulas formam as células e o aspecto membranoso é visto mais facilmente, a coloração que se destaca é alaranjada e ou amarelo claro (Fig. 5C). Além das escamas as asas também são providas de pelos sensoriais que estão dispersos por toda sua superfície.

O segmento final do corpo é o abdômen que se apresenta alongada, delgada, com coloração preta com manchas brancas e amarelas. Através da extremidade posterior do abdômen é possível fazer a sexagem dos indivíduos. A fêmea apresenta uma concavidade na porção final desse segmento (Fig. 6A) e no macho é arredondado sem nenhuma 
protuberância (Fig. 6B). O inseto adulto sobrevive em média 47 dias e o tempo médio de vida em torno de 90 dias a temperatura média no período de $25^{\circ} \mathrm{C}$.

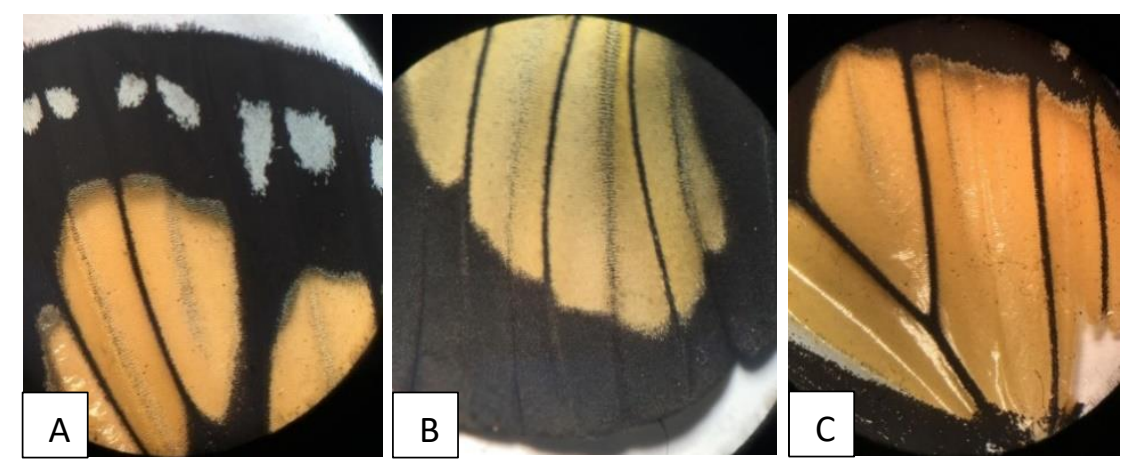

Figura 5- Aspecto das asas de Methona themisto. A. parte superior da asa com os pontilhados brancos na parte preta; B. parte inferior da asa com as bordas pretas; $\mathrm{C}$. parte interna da asa com presença de células e vênulas. Aumento de 16X.

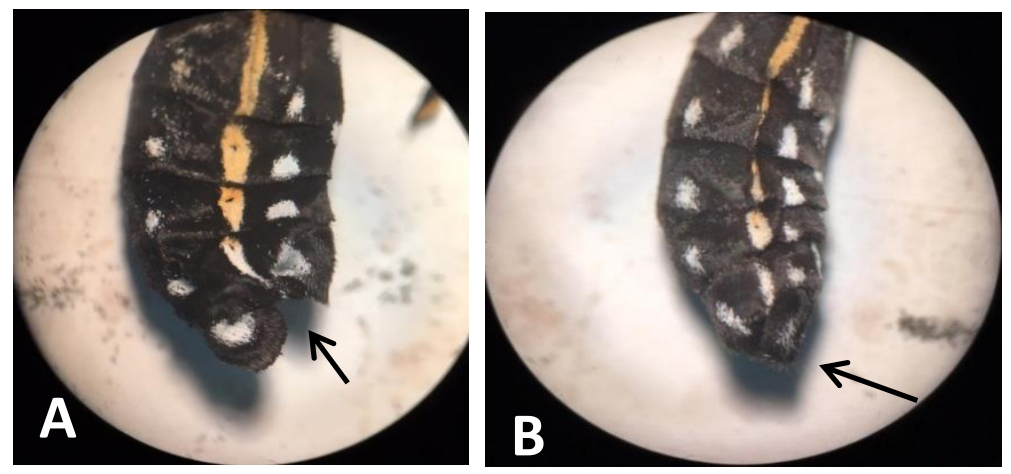

Figura 6-Methona themisto. A. Abdômen de fêmea; B. Abdômen de macho. Aumento de 16X.

Comparando os resultados quanto ao período de cada fase do ciclo de vida obtidos nesta pesquisa com os da literatura verificam-se semelhanças, no entanto, o ciclo total varia onde obtivemos em média 42 dias a temperatura média de $25^{\circ} \mathrm{C}$, enquanto que de SouzaJunior (2017) foi menor sendo o de 37,4 dias a temperatura média de $28,5^{\circ} \mathrm{C}$, e os de Marques, Camargo e Lacerda (2014) foram maiores em média de 49 dias da eclosão do ovo até a emergência do adulto, sem considerar o período de ovo o que tornaria o ciclo ainda mais longo, a temperatura média de $22^{\circ} \mathrm{C}$ (Tabela 1). Essa diferença pode ser devido as variações na temperatura. Quanto ao comprimento médio das lagartas nos diferentes instares os resultados obtidos variou de $4 \mathrm{~mm}$ no $1^{\circ}$ instar a $60 \mathrm{~mm}$ no $5^{\circ}$ instar sendo maiores do que os obtidos por Marques, Camargo e Lacerda (2014) que foi de 2,6mm a $36,1 \mathrm{~mm}$ e os resultados de Barbosa e Costa (2008) foi intermediário para $05^{\circ}$ instar que foi de $37,4 \mathrm{~mm}$ e maior para o $1^{\circ}$ instar sendo de $7 \mathrm{~mm}$. A temperatura mais baixa relatada por Marques, Camargo e Lacerda (2014) pode ter influenciado reduzindo a alimentação e consequentemente o menor tamanho das lagartas. As diferenças verificadas podem ser em decorrência das condições de criação, de cada região em que as variações de temperatura, umidade relativa do ar e alimentação podem interferir no desenvolvimento dos espécimes. Vale a pena ressaltar que a espécie da planta hospedeira que é utilizada para alimentação das lagartas podem interferir também nos resultados. 


\begin{tabular}{|c|c|c|c|c|c|c|c|c|c|}
\hline \multirow[t]{2}{*}{ Fase } & \multicolumn{3}{|c|}{ Resultados Obtidos } & \multicolumn{3}{|c|}{ Barbosa e Costa (2008) } & \multicolumn{2}{|c|}{$\begin{array}{c}\text { Marques et al. } \\
(2014)\end{array}$} & \multirow{2}{*}{$\begin{array}{c}\text { Souza-Junior } \\
(2017) \\
\begin{array}{c}\text { Período } \\
\text { (dias) }\end{array}\end{array}$} \\
\hline & $\begin{array}{l}\text { Comp. } \\
(\mathrm{mm})\end{array}$ & $\begin{array}{l}\text { Período } \\
\text { (dias) }\end{array}$ & $\begin{array}{l}\text { C.cef } \\
(\mathrm{mm})\end{array}$ & $\begin{array}{l}\text { Comp. } \\
(\mathrm{mm})\end{array}$ & $\begin{array}{l}\text { Período } \\
\text { (dias) }\end{array}$ & $\begin{array}{l}\text { C.cef } \\
(\mathrm{mm})\end{array}$ & $\begin{array}{l}\text { Comp. } \\
(\mathrm{mm})\end{array}$ & $\begin{array}{l}\text { Período } \\
\text { (dias) }\end{array}$ & \\
\hline Ovo & - & $6-7$ & & & $6-8$ & - & - & - & 6,7 \\
\hline $1^{\circ}$ instar & 4-7 & 4 & 0,8 & 7 & - & - & $2,6-5,7$ & 5 & - \\
\hline $2^{\circ}$ instar & $7-14$ & 4 & 1,0 & - & - & - & 8,8 & 4 & - \\
\hline $3^{\circ}$ instar & $14-25$ & 4 & 1,5 & - & - & - & 14,1 & 5 & - \\
\hline $4^{\circ}$ instar & $25-40$ & $5-6$ & 2,0 & - & - & - & 22,3 & 6 & - \\
\hline $5^{\circ}$ instar & $40-60$ & $8-10$ & 3,0 & 37,4 & - & 4 & 36,1 & 12 & - \\
\hline Lagarta & - & $25-28$ & - & - & - & - & - & 32 & 19,8 \\
\hline Pupa & - & $8-10$ & - & - & 14,2 & - & - & 17 & 10,9 \\
\hline TOTAL & & $39-45$ & & & - & & & 49 & 37,4 \\
\hline $\mathrm{T}^{\circ}$ & & $25^{\circ} \mathrm{C}$ & & & - & & & $22^{\circ} \mathrm{C}$ & $28,5^{\circ} \mathrm{C}$ \\
\hline
\end{tabular}

Tabela 1- Comparação do tamanho das lagartas e cápsula cefálica e o período das diferentes fases obtidas com os de Barbosa e Costa (2008), Marques et al. (2014) e Souza-Junior (2017). Comp.= comprimento; C.cef.= Cápsula cefálica; $\mathrm{mm}=$ milímetro.

\section{CONCLUSÃO}

Com a pesquisa constatou-se que o ciclo de vida de Methona themisto é em média 42 dias e seu tempo médio de vida em torno de 90 dias, sendo o tamanho da larva no primeiro instar de aproximadamente $4 \mathrm{~mm}$ e ao final do quinto instar em torno de $60 \mathrm{~mm}$, cada instar definido pelo tamanho da cápsula cefálica que varia de $0,8 \mathrm{~mm}$ a $3,0 \mathrm{~mm}$. A taxa de mortalidade foi baixa durante o manejo o que nos permitiu concluir que a espécie $M$. themisto apresenta um desenvolvimento favorável às condições laboratoriais, permitindo assim viabilidade para manutenção em borboletário.

\section{REFERÊNCIAS}

BARBOSA, K. V. C.; COSTA, T. V. V. Notes on the morphology and larval development of Methona themisto (Hübner, 1818) (Lepidoptera: Nymphalidae: Ithomiini) from southeastern Brazil. The Journal of Research on the Lepidoptera . v.46, p. 67-74. 2013

BECCALONI, George. W. Ecology, natural history and behaviour of Ithomiinae butterflies and their mimics in Ecuador. Tropical Lepidoptera. Londres, v. 8, n. 2, p. 103-124, 1997. Disponível em: www.troplep.org/TLR/8-2/pdf009.pdf. Acesso em: Outubro de 2018.

BUZZI, Zundir José. Entomologia didática. 4. ed. Curitiba: UFPR, 2002. Acesso em: Outubro de 2018. 
MARQUES, Beatriz Ribeiro; CAMARGO, Flávio de Vasconcelos; LACERDA, Fábio Vieira. Estudo dos instares da borboleta Methona themisto (Família Nymphalidae, Subfamília Ithomiinae) Revista Científica da FEPI, v. 6, 2014. Disponível em: https://pdfs.semanticscholar.org/baec/a5bbbea420176d3e930776887addb1 fd924e.pdf. Acesso em: Outubro de 2018.

NARDI, Cristiane; GUERRA, Tânia; ORTH, Afonso; TAVARES, Marcelo. Himenópteros parasitoides associados a pupas de Methona themisto (Lepidoptera, Nymphalidae) em Florianópolis, Santa Catarina, Brasil. Iheringia, Série Zoologia. v.96, n.3, p. 373-375. 2006 doi: 10.1590/ S0073-47212006000300014. Disponível em: http://www.scielo.br/scielo.php?script=sci_arttext\&pid=S0073$47212006000300014 \&$ Ing=pt\&nrm=iso\&tlng=pt. Acesso em: Outubro de 2018.

RAFAEL, José; MELO Gabriel; CARVALHO, Claudio; CASARI, Sonia; CONSTANTINO, Reginaldo. (Eds.).Insetos do Brasil: Diversidade e Taxonomia. Ribeirão Preto: Holos, 2012. Acesso em: Outubro de 2018.

RUSZCZYK, A.; NASCIMENTO, E. S. Biologia dos adultos Methona themisto (Hübner, 1818) (Lepidoptera, Nymphalidae) em praças públicas de Uberlândia, Minas Gerais, Brasil. Revista Brasileira de Biologia. v. 59, n. 4. p. 577 - 583. 1999. Disponível em: http://www.scielo.br/pdf/rbbio/v59n4/v59n4a06.pdf. Acesso em: Outubro de 2018.

SANTOS, Natália Larissa da Silva. Aspectos Biológicos de Caligoillioneus (Cramer, 1775) (Lepidoptera: Nymphalidae: Brassolinae) em Espécie e Heliconia (Heliconiacea). Universidade Federal de Alagoas CECA, 2009. Disponível em: http://www.repositorio.ufal.br/bitstream/riufal/241/3/Aspectos\%20biol\%C3\%B3gicos\%20de \%20Caligo\%20illioneus\%20\%28Cramer\%2C\%201775\%29\%20\%28Lepidoptera\%3A\%20 Nymphalidae\%3A\%20Brassolinae\%29\%20em\%20esp\%C3\%A9cies\%20de\%20Heliconia \%20\%28Heliconiaceae\%29.pdf. Acesso em: Outubro de 2018.

SOUZA-JUNIOR, G. Avaliação da viabilidade de Methona themisto (Lepidoptera: Nymphalidae) para criação em borboletário. Trabalho de Conclusão de Curso, Universidade Estadual de Maringá, Maringá, PR. 2017. Acesso em: Outubro de 2018.

TRIPLEHORN, C. A.; JONNSON, N. F. Estudo dos insetos. 7. ed. São Paulo: Cengage Learning, 2011. Acesso em: Outubro de 2018.

WATSON, L; DALLWITZ, M. J Insects of Britainandlreland: the families of Lepdoptera. 2003. Disponível em: delta-intkey.com/britin/lep/WWW/nymphali.htm. Acesso em: Outubro de 2018. 